\title{
Immunolocalization of G protein-coupled estrogen receptor in the rat epididymis
}

\author{
Griselle B. Martínez-Traverso ${ }^{1,2}$ and Christopher A. Pearl ${ }^{1 *}$
}

\begin{abstract}
Background: Estrogen plays an important role in male reproduction, and males lacking estrogen signaling in the reproductive tissues are infertile. Estrogen signaling is mediated via two nuclear receptors, ERa and ER $\beta$, but it was recently found that a $G$ protein-coupled estrogen receptor (GPER) is present in the testis. It is believed that GPER is a membrane form of the estrogen receptor and mediates non-classical estrogen signaling. However, the cellular localization of GPER in the epididymis is unknown. Therefore, the objective of this study was to determine the cellular and regional expression of GPER in the rat epididymis.

Findings: To localize expression, immunohistochemistry (IHC) was performed using fixed epididymal tissue. Three strains and ages of rats were used to identify whether GPER expression is strain or age specific. Our results are the first to demonstrate immunostaining of GPER in epididymal epithelial cells. Expression was highest near the apical membrane followed by the cytoplasm, consistent with a membrane bound receptor. The highest expression in adult rats was observed in corpus followed by cauda. Western blotting analysis of epididymal tissues from Sprague Dawley rats confirmed specificity of the antibody and regional expression.

Conclusions: Expression of GPER in the corpus and cauda suggests a role for non-classical estrogen signaling in sperm maturation in the corpus, and sperm protection/storage in the cauda. GPER expression pre-pubertally suggests that estrogen may have a role in epithelial cell development in addition to regulation of adult function.
\end{abstract}

Keywords: Estrogen receptor, Estrogen, Epididymis, GPER, Rat

\section{Findings}

\section{Background}

The epididymis serves as the link between the efferent ductules and the vas deferens in order for sperm to exit the testis. Transit through the epididymis is necessary for spermatozoa to completely mature, become motile and acquire fertility. This process can take up to two weeks in order for spermatozoa to travel through the entire epididymis. The principal function of the epididymis is regulating the luminal milieu to provide the proper environment for sperm maturation [1]. In addition to sperm maturation and sperm transport, the epididymis stores sperm prior to ejaculation [2].

The epididymis is regulated by androgen and estrogen signaling via androgen receptor (AR), or by the two nuclear estrogen receptors: estrogen receptor alpha $(\mathrm{ER} \alpha)$ and

\footnotetext{
* Correspondence: christopher.pearl@wmich.edu

'Department of Biological Sciences, Western Michigan University, Kalamazoo, Michigan, USA

Full list of author information is available at the end of the article
}

estrogen receptor beta $(E R \beta)$. AR is present in the nuclei of all epididymal regions and ER $\beta$ is present in the nuclei and cytoplasm of all epididymal regions in rats and other mammalian species [3-5]. ER $\alpha$ is present in epididymal epithelial cell nuclei and cytoplasm, and on the sperm in rats [3].

A third form of the estrogen receptor, G proteincoupled estrogen receptor (GPER), has been identified. GPER is expressed by immature Sertoli cells, pachytene spermatocytes and round spermatids in the rat testis [6-8]. GPER has been reported to be present in the epididymis based on mRNA and western blot analysis $[9,10]$ but GPER immunolocalization by region and cell type is still unknown. To better understand the role of GPER in epididymal function, this study was designed to determine the cellular and regional expression of GPER and investigate any difference between ages and strains of rats.
Ciomed Central

(c) 2015 Martinez-Traverso and Pearl; licensee BioMed Central. This is an Open Access article distributed under the terms of the Creative Commons Attribution License (http://creativecommons.org/licenses/by/4.0), which permits unrestricted use,

distribution, and reproduction in any medium, provided the original work is properly credited. The Creative Commons Public Domain Dedication waiver (http://creativecommons.org/publicdomain/zero/1.0/) applies to the data made available in this article, unless otherwise stated. 


\section{Methods}

Animals and tissue collection

Sprague Dawley, Brown Norway and Wistar rats were housed with free-will access to food and water until the desired age was reached. Adult, sexually mature Brown Norway $(n=4)$, Wistar $(n=3)$ and Sprague Dawley $(n=3)$ rats were used to investigate potential strain differences in
GPER expression. After euthanasia by $\mathrm{CO}_{2}$, epididymal tissue was dissected and fixed in $4 \%$ paraformaldehyde solution. Tissue was serially dehydrated and stored in $70 \%$ ethanol. Additionally, to investigate potential age differences, tissues were collected from three Sprague Dawley rats at 4- and 8-weeks of age. Tissue was embedded in paraffin wax and cut in $5 \mu \mathrm{m}$ slices that were mounted on

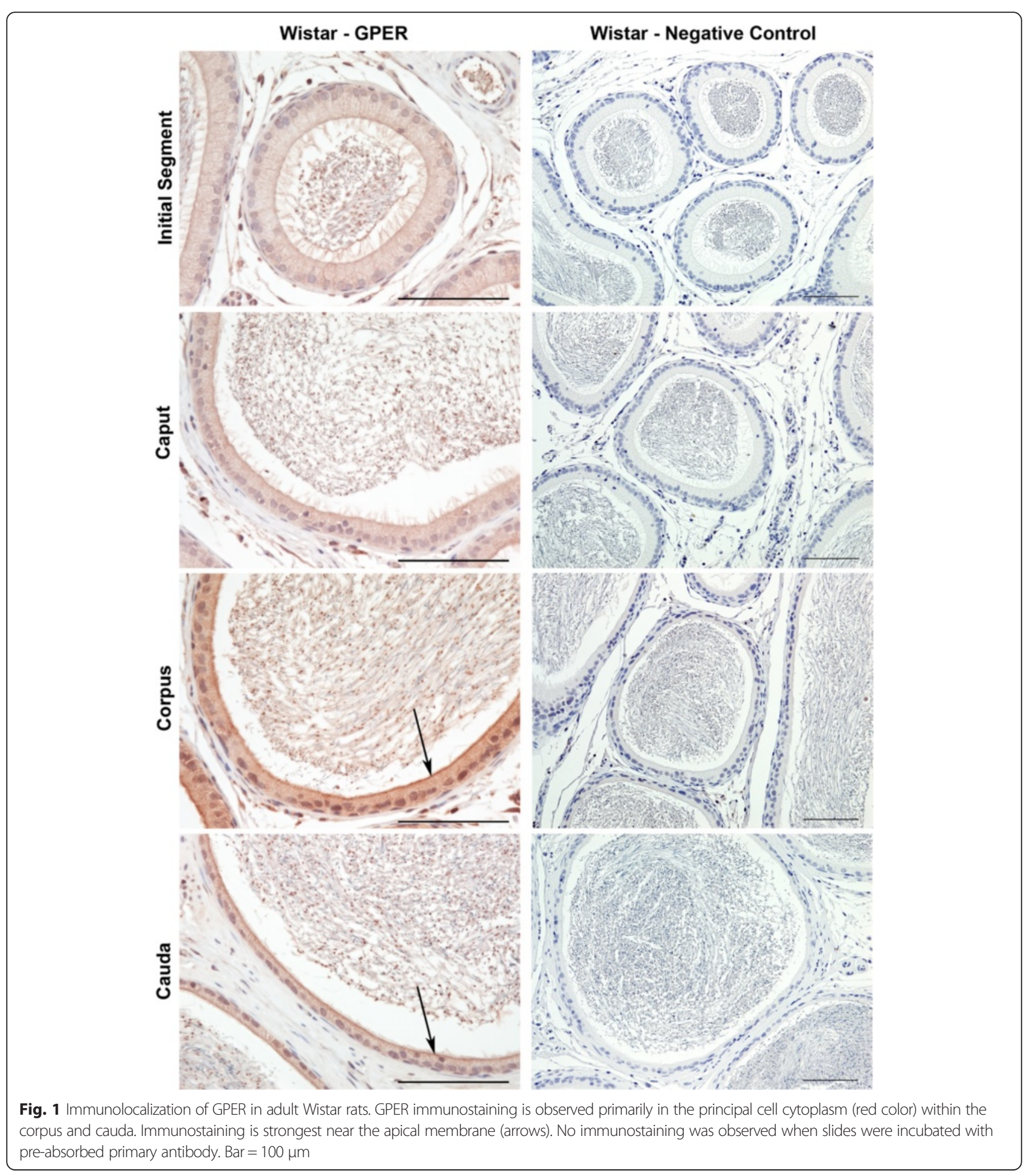


microscope slides for immunohistochemistry. All procedures had approval from the Western Michigan University Institutional Animal Care and Use Committee.

\section{Immunohistochemistry (IHC)}

The localization of GPER in the initial segment (IS), caput, corpus and cauda tissues was investigated by immunohistochemistry using a protocol similar to one previously described [3]. Tissue was paraffin embedded and sectioned at a thickness of $5 \mu \mathrm{m}$. Antigen retrieval was performed by submerging slides in a citric acid based antigen unmasking solution (Vector Laboratories, Inc., Burlingame $\mathrm{CA}$ ) in Coplin jars and steam heated to $93{ }^{\circ} \mathrm{C}$ for $5 \mathrm{~min}$ after which they were allowed to cool to
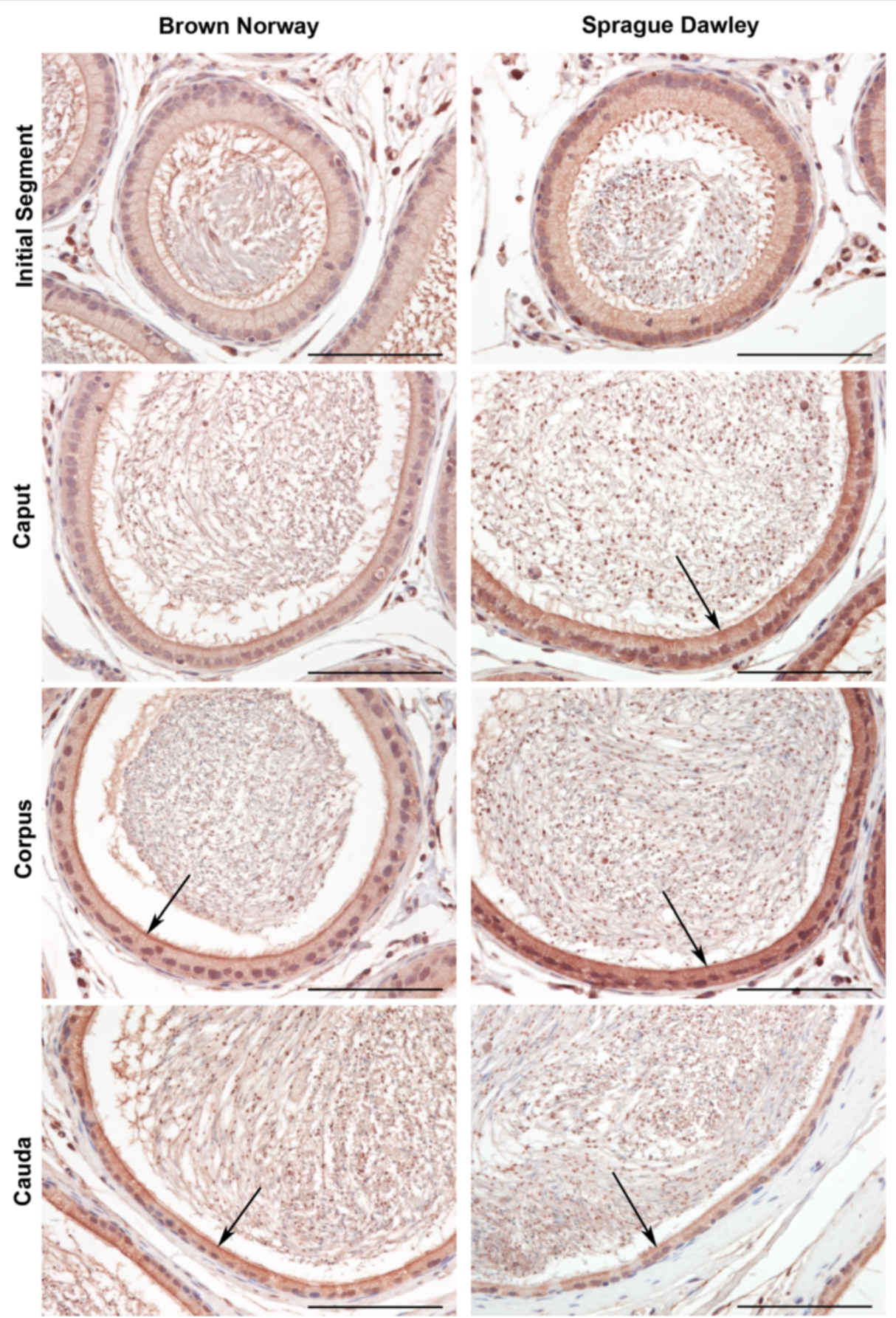

Fig. 2 Immunolocalization of GPER in adult Brown Norway and Sprague Dawley rats. GPER immunostaining is observed primarily in the principal cell cytoplasm (red color) within the corpus and cauda. Immunostaining is strongest near the apical membrane (arrows). Bar $=100 \mu \mathrm{m}$ 

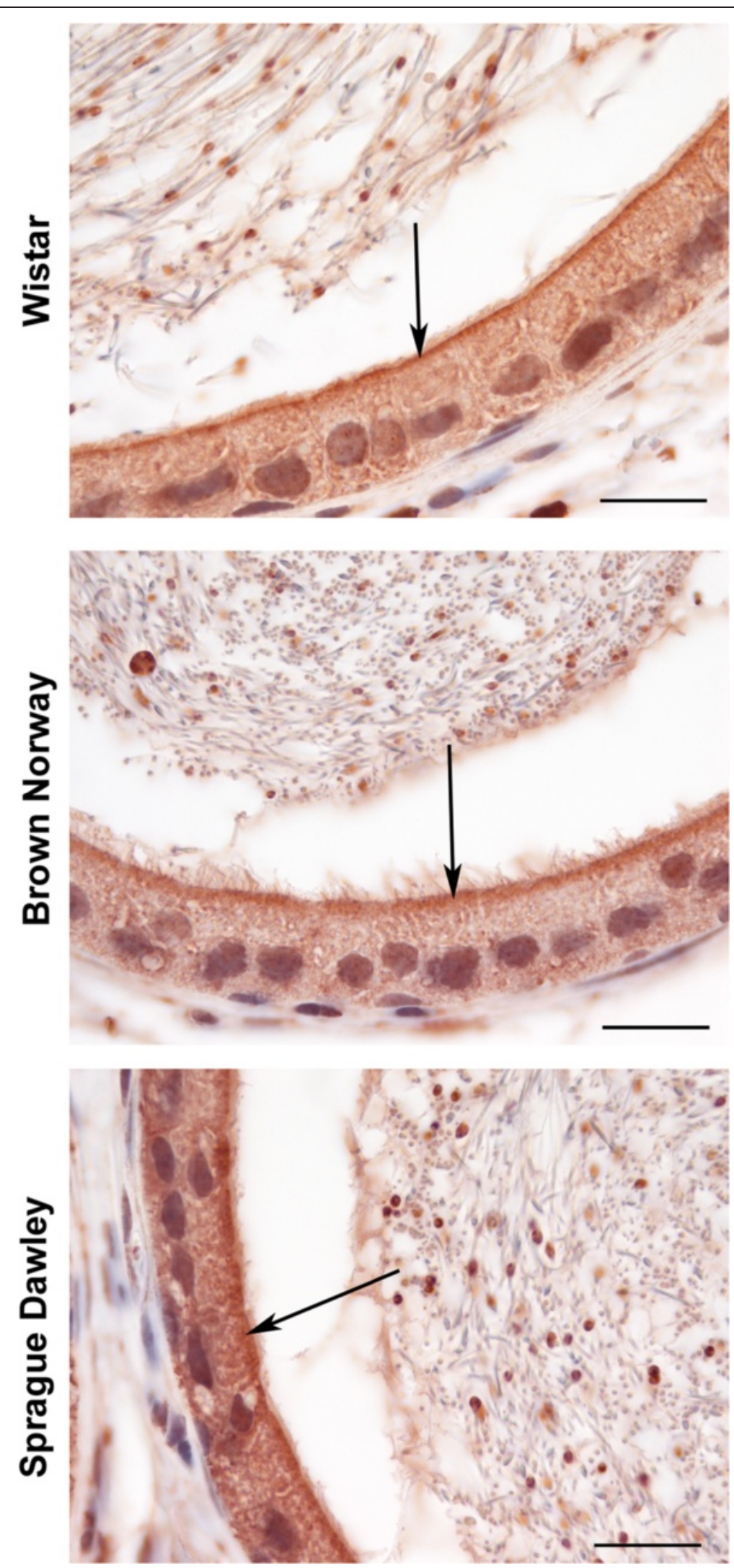

Fig. 3 (See legend on next page.) 
(See figure on previous page.)

Fig. 3 Immunolocalization of GPER in the corpus of adult Wistar, Brown Norway and Sprague Dawley rats at higher magnification.

GPER immunostaining is observed in the cytoplasm (red color) and immunostaining is strongest near the apical membrane

(arrows). Bar $=20 \mu \mathrm{m}$

room temperature. Endogenous peroxidase activity was blocked by incubation in $0.3 \%$ hydrogen peroxide in methanol for 30 minutes. After a blocking step, tissues were incubated for two hours at room temperature with rabbit anti-human GPR30 (1:2500; sc-48525; Santa Cruz Biotechnology). Following primary antibody incubation, sections were incubated with goat anti-rabbit biotinylated secondary antibody followed by an avidin-biotin horseradish peroxidase complex (Vector Laboratories). Immunostaining was visualized using NovaRed chromagen (Vector Laboratories). Pre-absorbed primary antibodies were substituted for primary antibody as a negative control; all other steps were identical including exposure times with NovaRed. All slides were counterstained with Immunomaster Hematoxylin and evaluated by light microscopy.

\section{Imaging}

Slides/tissues were visualized using a Nikon 80i microscope and images were taken with NIS Elements Software. Acquisition of images was done using a Nikon Digital Sight camera with NIS Elements Software. Intensity of immunostaining was scored as negative $(-)$, weak positive $(+)$, moderately positive $(++)$ or strong positive $(+++)$ by two independent observers.

\section{Western blotting}

Initial segment/caput, corpus and cauda were homogenized in a buffer consisting of $50 \mathrm{mM}$ Tris-Base, $10 \mathrm{mM}$ EDTA, $150 \mathrm{mM} \mathrm{NaCl}, 0.1 \%$ Tween 20 at pH 7.6. Homogenates were separated on a SDS-polyacrylamide gel with a MiniProtean Tetra System (BioRad; Hercules, CA, USA) using Precision Plus Protein molecular weight standards (BioRad) and transferred to an Immobilon-FL membrane (Millipore, Bedford, MA, USA). Membranes were blocked with $5 \%$ nonfat dry milk for one hour at room temperature. GPER antibody (1:250 in $5 \%$ nonfat dry milk) was incubated overnight at $4{ }^{\circ} \mathrm{C}$. Pre-absorbed primary antibody and actin antibody were also incubated overnight at $4{ }^{\circ} \mathrm{C}$. Membranes were washed and incubated with alkaline phosphatase-conjugated goat antirabbit IgG (Applied Biosystems) diluted 1:10,000 in $5 \%$ nonfat dry milk for one hour at room temperature. Membranes were visualized with chemiluminescence (Tropix CSPD with Nitro Block; Applied Biosystems) and exposed on Blue Basic AutoRad film (Bioexpress; Kaysville, UT, USA).

\section{Results}

GPER immunostaining was observed primarily in the principal cell cytoplasm of adult Wistar (Fig. 1), Brown Norway (Fig. 2) and Sprague Dawley (Fig. 2) rats. In the cytoplasm, the most intense immunostaining was observed near the luminal/apical membrane giving the appearance of an apical ring. Immunostaining in all three strains was highest in the corpus followed by the cauda (Fig. 3; Table 1). The initial segment and caput displayed weak immunostaining in Wistar and Brown Norway rats while these regions were moderately positive in Sprague Dawley rats (Table 1). In contrast to ER $\alpha$ and $E R \beta$ which display strong nuclear staining [3], nuclei in the corpus and cauda of adult animals were weakly positive for GPER immunostaining. In four week old pre-pubertal Sprague Dawley rats, GPER immunostaining was strongest in the cauda, while epithelial cytoplasm was also positive in the initial segment, caput and corpus (Fig. 4). In eight week old peri-pubertal Sprague Dawley rats, the immunostaining pattern was similar to that observed in adult rats (Fig. 4). Tissues incubated with pre-absorbed primary antibody were negative for GPER immunostaining (Fig. 1).

Using western blot analysis, a primary protein band was observed at $43 \mathrm{kD}$ and a secondary band was observed at $55 \mathrm{kD}$ in epididymal tissues from Sprague Dawley rats (Fig. 5). GPER has been reported as a $43 \mathrm{kD}$ protein in the rat testis $[7,8]$ and a $55 \mathrm{kD}$ protein in the epididymis of Wistar rats [10] and our antibody appears to detect both

Table 1 Summary of GPER immunostaining in the epididymis of adult Sprague Dawley (SD), Brown Norway (BN) and Wistar rats

\begin{tabular}{lllll}
\hline Region & Rat Strain & Cytoplasm & Apical Surface & Nuclei \\
\hline Initial Segment & Adult SD & ++ & $+/-$ & - \\
& Adult BN & + & $+/$ & - \\
\multirow{5}{*}{ Caput } & Adult Wistar & + & $+/-$ & - \\
& Adult SD & ++ & +++ & - \\
& Adult BN & + & ++ & - \\
Corpus & Adult Wistar & + & + & - \\
& Adult SD & +++ & +++ & + \\
& Adult BN & ++ & +++ & + \\
Cauda & Adult Wistar & ++ & +++ & + \\
& Adult SD & ++ & ++ & $+/-$ \\
& Adult BN & ++ & +++ & $+/-$ \\
& Adult Wistar & + & ++ & + \\
\hline
\end{tabular}

Intensity of immunostaining was scored as negative (-), weak positive (+), moderate positive $(++)$ or strong positive $(+++)$ 


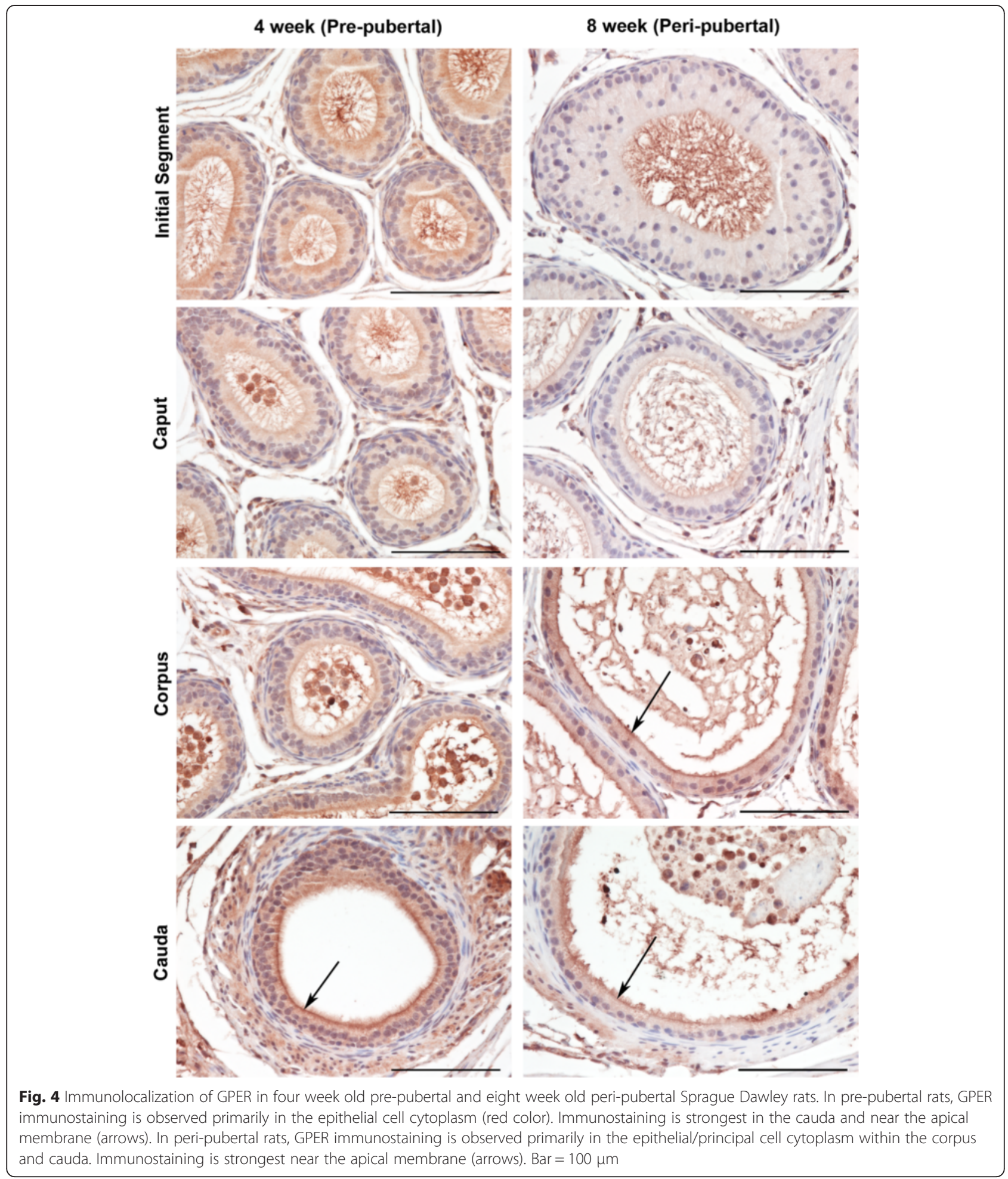

forms. Expression of the $43 \mathrm{kD}$ protein appeared similar between epididymal regions while expression of the $55 \mathrm{kD}$ band appeared stronger in the corpus and cauda compared with the IS/caput. The western blot results as currently performed were not designed to confirm the subcellular localization of GPER, however, they do confirm antibody specificity and provide support for immunohistochemistry results suggesting lower GPER expression in the initial segment/caput. 


\section{A GPER}

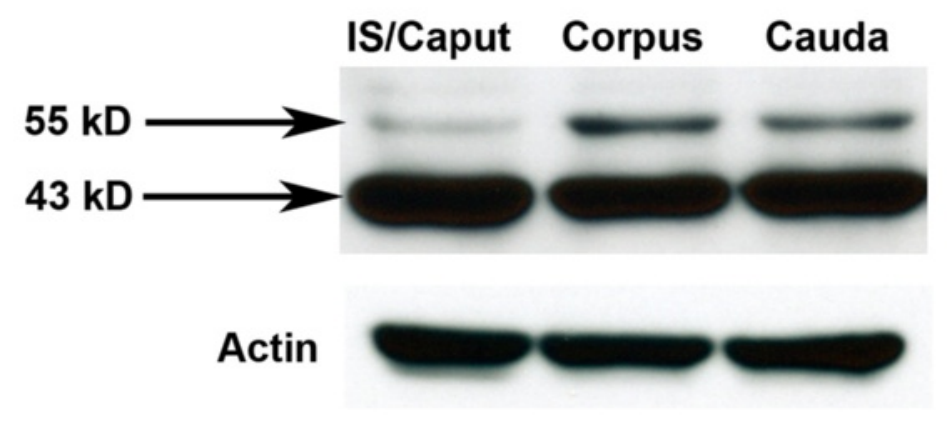

B Pre-absorbed primary

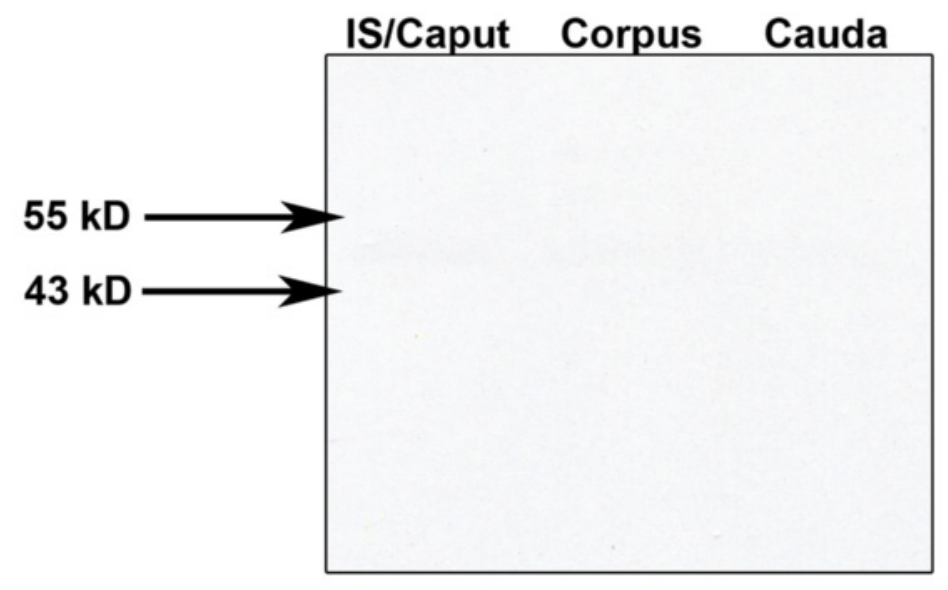

Actin

Fig. 5 Western blot for GPER in the IS/caput, corpus and cauda from Sprague Dawley rats. a Proteins of appropriate molecular weight for GPER were observed at $43 \mathrm{kD}$ and $55 \mathrm{kD}$. Equal amounts of protein were loaded into each lane which was confirmed by actin immunoblotting. b No protein bands were observed when membranes were incubated with pre-absorbed primary antibody. Images shown are representative of results from three separate animals

\section{Discussion}

Our results demonstrate the cellular localization and regional expression pattern of GPER in the epididymis of multiple strains of rats and at various developmental stages. In adult animals, GPER was expressed primarily in the corpus and cauda with lower expression observed in the initial segment and caput. Our results are consistent with previous reports measuring GPER protein via western blotting [10] and mRNA [9] that observed the highest expression in the corpus of Wistar rats. The expression pattern of GPER was quite similar in Wistar and Brown Norway rats. Sprague Dawley rats show a broader expression since the caput and initial segment have a stronger immunostaining in these regions compared to the other strains examined. ER $\alpha$ and ER $\beta$ exhibit nuclear expression and function as classical nuclear receptors and transcription factors. GPER expression was primarily cytoplasmic suggesting that estrogen action via GPER may be a separate signaling pathway from the nuclear receptors ER $\alpha$ and ER $\beta$. Expression of GPER is highest in the corpus, but interestingly, concentrations of estradiol in the corpus of Wistar rats have been reported be significantly lower than the IS/caput and cauda [10].

In the rat testis, GPER is expressed by pachytene spermatocytes, round spermatids and Sertoli cells where it appears to function in cell differentiation and regulation of apoptosis [6-8]. While the function of GPER in the epididymis remains to be determined, it may be related 
to the regulation of regional gene expression. Epididymal gene expression is region specific with genes such as beta-defensins and lipocalins showing higher expression in the corpus [11-13]. Proteins such as lactoferrin and clusterin also show higher expression in the corpus, compared to other epididymal regions $[14,15]$. In general, the percentage of mature sperm greatly increases in the corpus where GPER expression is highest, which suggests GPER signaling may have a role in sperm maturation. Also, since GPER is expressed in the cauda where sperm are stored, GPER signaling may be important for sperm protection and storage. The presence of GPER in pre-pubertal rats suggests that the estrogen signaling via GPER may have a function in epithelial cell development. GPER expression in peri-pubertal rats suggests that the estrogen signaling via GPER may also play a role in epithelial differentiation and maturation.

In conclusion, our results suggest that non-classical estrogen signaling via GPER may exist in the epididymis and contribute to sperm maturation in the corpus and storage in the cauda.

\section{Competing interests}

The authors declare that they have no competing interests.

\section{Authors' contributions}

Conceived and designed the experiments: GBMT, CAP. Performed the experiments: GBMT, CAP, Analyzed the data: GBMT, CAP. Wrote the initial manuscript draft: GBMT. Edited and prepared the final manuscript: CAP. Both authors read and approved the final manuscript.

\section{Acknowledgments}

This work was supported by NSF-REU Grant \#1062883 and a WMU FRACAA.

\section{Author details}

'Department of Biological Sciences, Western Michigan University, Kalamazoo, Michigan, USA. ${ }^{2}$ Departments of Biology and Industrial Microbiology,

University of Puerto Rico, Mayagüez, Puerto Rico.

Received: 4 November 2014 Accepted: 7 May 2015

Published online: 27 May 2015

\section{References}

1. Robaire B, Hinton B, Orgebin-Crist M-C. The Epididymis. In: Neill JD, editor. Knobil and Neill's Physiology of Reproduction. Volume 1. Thirdth ed. New York: Elsevier; 2006. p. 1071-147.

2. Cooper TG. Epididymis and sperm function. Andrologia. 1996;28 Suppl 1:57-9.

3. Zaya R, Hennick C, Pearl CA. In vitro expression of androgen and estrogen receptors in prepubertal and adult rat epididymis. Gen Comp Endocrinol. 2012;178:573-86

4. Parlevliet JM, Pearl CA, Hess MF, Famula TR, Roser JF. Immunolocalization of estrogen and androgen receptors and steroid concentrations in the stallion epididymis. Theriogenology. 2006;66:755-65.

5. Pearl CA, Berger T, Roser JF. Estrogen and androgen receptor expression in relation to steroid concentrations in the adult boar epididymis. Domest Anim Endocrinol. 2007:33:451-9.

6. Lucas TF, Royer C, Siu ER, Lazari MF, Porto CS. Expression and signaling of G protein-coupled estrogen receptor 1 (GPER) in rat sertoli cells. Biol Reprod. 2010;83:307-17.

7. Chimento A, Sirianni R, Delalande C, Silandre D, Bois C, Ando S, et al. 17 beta-estradiol activates rapid signaling pathways involved in rat pachytene spermatocytes apoptosis through GPR30 and ER alpha. Mol Cell Endocrinol. 2010;320:136-44.
8. Chimento A, Sirianni R, Zolea F, Bois C, Delalande C, Ando S, et al. Gper and ESRs are expressed in rat round spermatids and mediate oestrogen-dependent rapid pathways modulating expression of cyclin B1 and Bax. Int J Androl. 2011;34:420-9.

9. Hess RA, Fernandes SA, Gomes GR, Oliveira CA, Lazari MF, Porto CS. Estrogen and its receptors in efferent ductules and epididymis. J Androl. 2011;32:600-13.

10. Pereira MF, Fernandes SA, Nascimento AR, Siu ER, Hess RA, Oliveira CA, et al. Effects of the oestrogen receptor antagonist Fulvestrant on expression of genes that affect organization of the epididymal epithelium. Andrology. 2014;2:559-71.

11. Jelinsky SA, Turner TT, Bang HJ, Finger JN, Solarz MK, Wilson E, et al. The rat epididymal transcriptome: comparison of segmental gene expression in the rat and mouse epididymides. Biol Reprod. 2007;76:561-70.

12. Thimon V, Calvo E, Koukoui O, Legare C, Sullivan R. Effects of vasectomy on gene expression profiling along the human epididymis. Biol Reprod. 2008;79:262-73.

13. Belleannee $C$, Thimon $V$, Sullivan R. Region-specific gene expression in the epididymis. Cell Tissue Res. 2012;349:717-31.

14. Dacheux JL, Belleannee C, Jones R, Labas V, Belghazi M, Guyonnet B, et al. Mammalian epididymal proteome. Mol Cell Endocrinol. 2009;306:45-50.

15. Pearl CA, Roser JF. Lactoferrin expression and secretion in the stallion epididymis. Reprod Biol. 2014;14:148-54.

\section{Submit your next manuscript to BioMed Central and take full advantage of:}

- Convenient online submission

- Thorough peer review

- No space constraints or color figure charges

- Immediate publication on acceptance

- Inclusion in PubMed, CAS, Scopus and Google Scholar

- Research which is freely available for redistribution 